\title{
A UNUSAL PRESENTATION OF BARTTER SYNDROME
}

\section{General Medicine \\ Nitharsha Prakash M} Hospital, Chromepet, Chennai-44

N Nag Anand*

Professor, Department of General Medicine, Sree Balaji Medical College and Hospital, Chromepet, Chennai- 44 * Corresponding Author

\section{ABSTRACT}

Bartter Syndrome is a rare congenital disease that manifests as hypokalemia, hyponatremia and hypotension. The disease occurs due to defective genes that are responsible for the reabsorption of certain electrolytes in the renal tubules. Hence it results in salt-wasting dyselectrolytemia. By its inheritable nature, the usual presentation of the disease is in the infants and children. But this case report presents an adult with symptoms of Bartter Syndrome which was discovered by chance while the patient was being treated for Acute gastroenteritis. Adult onset of Bartter Syndrome is incredibly rare and has been reported only in few other cases.

\section{KEYWORDS}

hypokalemia, Bartter Syndrome, kidney, dyselectrolytemia, hypomagnesemia

\section{INTRODUCTION}

Bartter syndrome is an uncommon salt wasting disease due to defect in the thick ascending limb of the loop of Henle. The disease presents with increased $\mathrm{pH}$ of blood (metabolic alkalosis), hypokalemia and hypotension or normal blood pressure ${ }^{(1)}$.

It occurs as a result in mutations in any of a number of genes. Based on the defective gene, the disease has been classified into various types. SLC12A1 gene mutation is Type I Bartter Syndrome, KCNJ1 mutation is Type $\mathrm{II}^{(9)}$. Type III is a result of CLCNKB mutation ${ }^{(9)}$. Type IV occurs due to BSND mutation or Mutations of CLCNKA and CLCNKB genes. It is not possible to identify a defective gene in all of the patients with Bartter syndrome, which indicates that not all the disease causing mutations has not yet been identified ${ }^{(2)}$. The above mentioned genes play a role in normal transport function of thick ascending limb in loop of Henle in the kidneys.

As a result of the above mentioned genes and genes yet undiscovered, there is abnormal functioning of sodium, potassium and chloride cotransporter in the thick ascending limb of loop of Henle ${ }^{(3)}$. This leads to loss of electrolytes presenting with the clinical picture seen in the disease.

\section{CASE REPORT}

\section{HISTORY:}

A 65 years old female patient presented with complaints of lightheadedness for 3 days not associated with vertigo. She also complains of multiple episodes of loose stools, watery in consistency, not blood stained. Patient has history of easy fatigability. No history of fever, vomiting, headache. No history of cough, sore throat or breathlessness. No history of profuse sweating. No history of abdominal pain. No history of intake of any diuretics, laxatives or any other medications. She has no comorbidities. Patient has history of being treated with IV fluids multiple times in view of hypotension

\section{EXAMINATION}

On examination patient was conscious, oriented to time, place and person and afebrile. BP- 90/60mmHg, PR- 74bpm, SpO2-99\% at room air. No skin hyperpigmentation or rashes. Chest sounds were normal and lung fields were clear. Per abdomen- soft, bowel sounds heard and no organomegaly. CNS examination revealed no focal neurologic defects.

\section{COURSE}

With suspicion of Acute Gastroenteritis with moderate dehydration, patient was started on supportive therapy and necessary investigations were sent. Serum Potassium was found to be $2.66 \mathrm{mg} / \mathrm{dl}$ (decreased), Serum Sodium- $141.1 \mathrm{mg} / \mathrm{dl}$, Serum Chloride $103 \mathrm{mg} / \mathrm{dl}$. In view of hypokalemia, $15 \mathrm{ml}$ of Potassium citrate syrup was given in a glass of water thrice daily. Patient bowel movements returned to normal. Urine routine was reported to be normal. Urea was $18 \mathrm{mg} / \mathrm{dl}$, Creatinine $1.5 \mathrm{mg} / \mathrm{dl}$ and Uric Acid $8.4 \mathrm{mg} / \mathrm{dl}$ (elevated).
On repeating Serum Potassium six hours after correction, it deteriorated to $1.92 \mathrm{mg} / \mathrm{dl}$ for which patient was started on Inj KCL at $80 \mathrm{meq}$ in $500 \mathrm{ml} \mathrm{NS}$ at $75 \mathrm{ml} / \mathrm{hr}$. Four hours later patient serum potassium further dropped to $1.63 \mathrm{mg} / \mathrm{dl}$. BP was found to be $80 / 50 \mathrm{mmHg}$. For purpose of cardiac monitoring and intensive care, patient was shifted to ICU and ECG and ABG was done. Liver function tests were within normal limits. 24 hours urine chlorine was $252 \mathrm{mmol}$, calcium $320 \mathrm{mg}$.

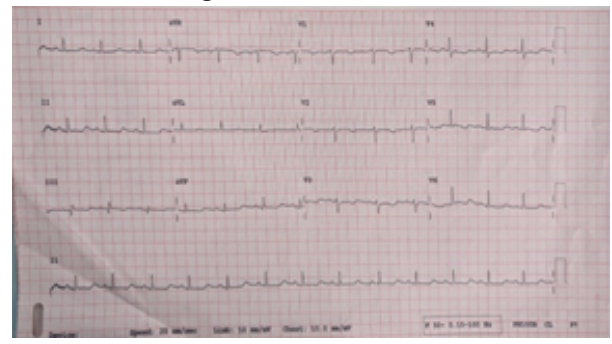

Figure 1: ECG showing features of hypokalaemia (q wave in II, III and avF, Twave inversion in V2-V6 and QT prolongation)

ECG showed changes corresponding to hypokalemia and ABG revealed metabolic alkalosis. Serum Magnesium was found to be $1.4 \mathrm{mg} / \mathrm{dl}$ and Serum Ca was $6.7 \mathrm{mg} / \mathrm{dl}$. Troponin T was negative. 24hour Urine potassium was found to be $155.5 \mathrm{mg} / \mathrm{dl}$. Urine osmolality was found to be $181 \mathrm{mOsm} / \mathrm{kg}$. Serum Cortisol was found to be $111.04 \mathrm{mcg} / \mathrm{dl}$ A diagnosis of Bartter Syndrome was made due to presence of hypokalemia, hypocalcemia, hypotension, hyperuricaciduria and metabolic alkalosis. Patient doesn't have history and the clinical features suggestive of laxative abuse, diuretics use, bulimia, gentamicin nephrotoxicity, Sjogren's syndrome, and cystic fibrosis which are can mimic Bartter Syndrome (called as PesudoBartter Syndrome). Low urinary calcium excretion rules out Gitelman Syndrome. Patient was immediately administered with $\mathrm{MgSo} 42 \mathrm{gm}$ iv, injection calcium gluconate, Tab Aldactone $0.25 \mathrm{mg} \mathrm{BD}$, Inj Kcl $60 \mathrm{meq}$ iv over 6 hours was given. Inotropic support was given with Injection Noradrenaline to maintain BP.

\section{OUTCOME}

Hypokalemia began to improve after hypocalcemia and hypomagnesemia was corrected. Patient improved symptomatically. Patient was discharged with the advice of potassium and calcium rich diet. The patient was reviewed as outpatient two weeks later with reports which showed normal serum potassium levels and patient had no complaints of fatigue or giddiness.

\section{DISCUSSION}

Bartter's syndrome consists of hypokalemia due to renal potassium wasting, normal or low blood pressure, hypo responsiveness of blood pressure to infused angiotensin II elevated plasma renin activity and aldosterone secretion, and hyperplasia of granular cells of the 
juxtaglomerular apparatus of the kidney. Proximal muscle weakness may cause easy fatigability and force patients to seek medical care ${ }^{(4)}$.

Gastrointestinal symptoms include anorexia and constipation due to renal water loss and hypokalemic ileus ${ }^{(4)}$. There are two common presentations in Bartter's Syndrome. The first one, called as Neonatal Bartter Syndrome presents during intrauterine life with polyuria which causes polyhydramnios and the other being Classic Bartter Syndrome which presents during child hood with features of polyuria, polydipsia and muscle weakness. In a very rare instance, adults present with tetany, easy fatigability and muscle weakness ${ }^{(6)}$.

The etiology of Bartter syndrome remains undiscovered ${ }^{(2)}$. Many suggest that defects in urinary prostaglandin homeostasis as the primary abnormality. Peripheral vasodilation and non-responsiveness to pressors can be explained by elevated by prostaglandins ${ }^{(2)}$. But prostaglandin inhibition has not been found to be useful in Bartter syndrome ${ }^{(2)}$. It is now assumed that there is a possibility of multiple underlying etiology ${ }^{(7)}$.

It is important to rule out causes of pseudo-Bartter syndrome, which presents with similar clinical picture but due to varying etiology and pathology. Some these are: use of laxative, loop diuretics, bulimia. Use of Loop diuretics cause renal potassium wasting and hypovolemia resulting in a clinical picture resembling Bartter Syndrome ${ }^{(1)}$

The primary goal of management is to revert hypokalemia as it predisposes the patient to risk of cardiac arrhythmias ${ }^{(1)}$. Hypomagnesemia can result in refractory hypokalemia ${ }^{(1)}$, which makes magnesium correction an essential part of treatment. Other medications include potassium sparing diuretics, beta blockers, potassium supplementation and magnesium repletion and prostaglandin inhibitors ${ }^{(3)}$. But the results of use of many of the above mentioned drugs have not produced satisfactory effect.

\section{CONCLUSION}

The patient although she had frequent episodes of hypotension, was never evaluated the cause for the same at any point in her life. This led to the late discovery of the inherited disorder in her. Although there have been few reported cases of Bartter's in adults ${ }^{(4),(5),(10),(11)}$, it is incredibly rare. While it is common in men, the diagnosis of Bartter's syndrome in an elderly female makes it an unusual presentation. While being evaluated, hypokalemia was discovered and attributed initially to the diarrhea. However, failure to increase in potassium levels in spite of therapy raised questions of hypomagnesemia which was confirmed on further investigations. The presence of metabolic alkalosis and above mentioned dyselectrolytemia points to the diagnosis of Bartter syndrome in an unlikely presentation on an unlikely patient.

\section{REFERENCES:}

1. Kasper, Dennis L, editor. Harrison's Principles of Internal Medicine. 19th edition editors, Dennis L. Kasper, MD, William Ellery Channing, Professor of Medicine, editors, Dennis L. Kasper, MD, William Ellery Channing, Professor of Medicine,
Professor of Microbiology, Department of Microbiology and Immunobiology, Harvard Medical School, Division of Infectious Diseases, Brigham and Women's Hospital, Boston, Massachusetts [and five others], McGraw Hill Education, 2015

2. Stein, J. H. (1985). The pathogenetic spectrum of Bartter's syndrome. Kidney international, 28(1), 85-93.

3. Taal, Maarten W., et al., editors. Brenner \& Rector's the Kidney. 9th ed, Elsevier/Saunders, 2012.

4. Park, Jong Wook, et al. "A Case of Adult-Onset Bartter`s Syndrome." The Korean Journal of Internal Medicine, vol. 10, no. 1, Jan. 1995, pp. 60-63. DOI.org (Crossref), doi:10.3904/kjim.1995.10.1.60

5. Tomko, D. J., Yeh, B. P., \& Falls Jr, W. F. (1976). Bartter's syndrome: Study of a 52 year old man with evidence for a defect in proximal tubular sodium reabsorption and comments on therapy. The American journal of medicine, 61(1), 111-118.

6. White, M. G. (1972). Bartter's syndrome: a manifestation of renal tubular defects. Archives of internal medicine, 129(1), 41-47.

7. Baehler, R. W., Work, J., Kotchen, T. A., McMorrow, G., \& Guthrie, G. (1980). Studies on the pathogenesis of Bartter's syndrome. The American journal of medicine, 69(6), 933-938.

8. "Bartter Syndrome and Gitelman Syndrome - Children's Health Issues," Merck Manuals Consumer Version, https://www.merckmanuals.com/home/children-s-healthManuals Consumer Version, https://www.merckmanuals.com/home/children-s-health-
issues/congenital-kidney-tubular-disorders/bartter-syndrome-and-gitelman-syndrome. issues/congenital-kidney-tubular-disorders/bartter-syndrome-and-gitelman-syndrome.
Accessed 28 June 2019 .

9. Seyberth, H. W. (2008). An improved terminology and classification of Bartter-like syndromes. Nature Reviews Nephrology, 4(10), 560

10. Brum, S., Rueff, J., Santos, J. R., \& Calado, J. (2006). Unusual adult-onset manifestation of an attenuated Bartter's syndrome type IV renal phenotype caused by a mutation in BSND. Nephrology Dialysis Transplantation, 22(1), 288-289.

11. Huang, L., Luiken, G. P., van Riemsdijk, I. C., Petrij, F., Zandbergen, A. A., \& Dees, A. (2014). Nephrocalcinosis as adult presentation of Bartter syndrome type II. Neth J Med, 72(2), 91-93. 